Eixo Temático: Desenvolvimento de Estratégias Didáticas

\title{
ET-07-016 \\ CÉLULAS ANIMAIS E VEGETAIS CONFECCIONADAS A PARTIR DE MATERIAL RECICLÁVEL POR ALUNOS DE UMA ESCOLA MUNICIPAL DE IMPERATRIZ-MA
}

Reginaldo Ferreira da Mota ${ }^{1}$, Caio César Silva Lima ${ }^{1}$, Maria Giselhe Ribeiro da Cruz Cantuária1 ${ }^{1}$, Marcelo Soares dos Santos², Leonardo Hunaldo dos Santos²

${ }^{1}$ Bolsista do Programa Institucional de Bolsa de Iniciação à Docência -PIBID - Licenciatura em Ciências Naturais/Biologia - Maranhão.

2Universidade Federal do Maranhão².

http://dx.doi.org/10.21472/congrebio2016.et-07-016

\section{RESUMO}

Com o intuito de despertar a curiosidade e imaginação de alunos do ensino fundamental junto ao aprendizado de Ciências, além de motivá-los a integração em grupo, este estudo baseiase na confecção de modelos de célulasanimais e vegetaisa partir do uso de material reciclável e debaixo custo. A realização da prática ocorreu numaturma de $7^{\circ}$ do ensino fundamental de uma escola da rede pública. Os materiais para a confecção, emsua grande maioria, seriam aqueles a serem descartados, envolvendo desde garrafas PET a palitos de picolé. A atividade envolveu a apresentação do tema e designações de tarefas, e processo de confecção dos modelos durante três semanas. No final do processo, seis modelos de células, três animais e três vegetais, foram confeccionados pelos estudantes. Houve uma conscientização sobre destino do lixo, bem como o desenvolvimento de estratégias pedagógicas para auxiliar no ensino de Ciências.

Palavras-chave: PIBID; Reciclagem; Modelos didáticos; Práticas pedagógicas.

\section{INTRODUÇÃO}

Com atividades lúdicas que permitem o ensino e aprendizado de maneira mais eficaz, os alunos desenvolvem suas habilidades e aumentam sua interação com o grupo e com o conteúdo aplicado. Percebe-se que a busca do saber se torna importante e prazerosa quando a criança aprende brincando, sendo assim uma forma de aprendizagem menos rígida, de maneira alegre e divertida (SCHOENBERGER, 2010).

Utilizando materiais recicláveis estimula-se a imaginação das crianças e motiva-as a buscar por maneiras e formas novas de aprendizado. Além de que a produção de material didático usando material reciclável é de baixo custo e pode ser utilizada como ferramenta de ensino em escolas, principalmente públicas.

O processo de confeccionar material didático envolvendo os alunos surge como uma alternativa no processo do ensino de Ciências e especificamente sobre o ensino das células. Na prática, enquanto ocorre o processo da atividade lúdica, o professor pode ensinar os conceitos das estruturas envolvidas na constituição celular.

Portanto, a metodologia de confeccionar material didático com o uso de material reciclávelé uma ferramenta para estimulo da imaginação, diversão e aprendizado dos alunos, visando auxiliar seu aprendizado no ensino de ciências e o seu desenvolvimento na sala de aula. Desta forma, tornou-se objetivo deste estudo, confeccionar modelos de células animais e vegetais utilizando material reciclável didático com o intuito de facilitar o aprendizado em Ciências. 


\section{OBJETIVOS}

Confeccionar modelos de células, animais e vegetais, como material didático, para uso como ferramenta facilitadora do ensino de Ciências. Bem como promover interações de equipes na confecção do material e conscientizar sobre o destino e uso de material reciclável.

\section{MÉTODOS}

O trabalho faz parte das atividades do Programa Institucional de Bolsa de Iniciação à Docência (PIBID) realizado pelo Subprojeto da Licenciatura em Ciências Naturais com ênfase em Biologia. Este estudo é de cunho qualitativo.Foi realizado em uma escola de ensino fundamental da cidade de Imperatriz-MA, com alunos do $7^{\circ}$ Ano, em um total de 36 alunos, sendotrês encontros semanais de 01:40h cada.

No primeiro, reunidos com a turma, foi demonstrado o projeto a ser trabalhado, utilizando figuras ilustrativas sobre células do livro de Ciências usado na turma (Figuras 1 a 6). As motivações que nos levaram a propor usar material reciclável para a confecção de material didático. Uma vez que o material produzido por eles seria utilizado como ferramenta nas aulas referentes aos estudos sobre células. Logo após de explicar os objetivos, foi sugerido que os alunos se dividissem em grupos, cada um destes, com seis alunos.

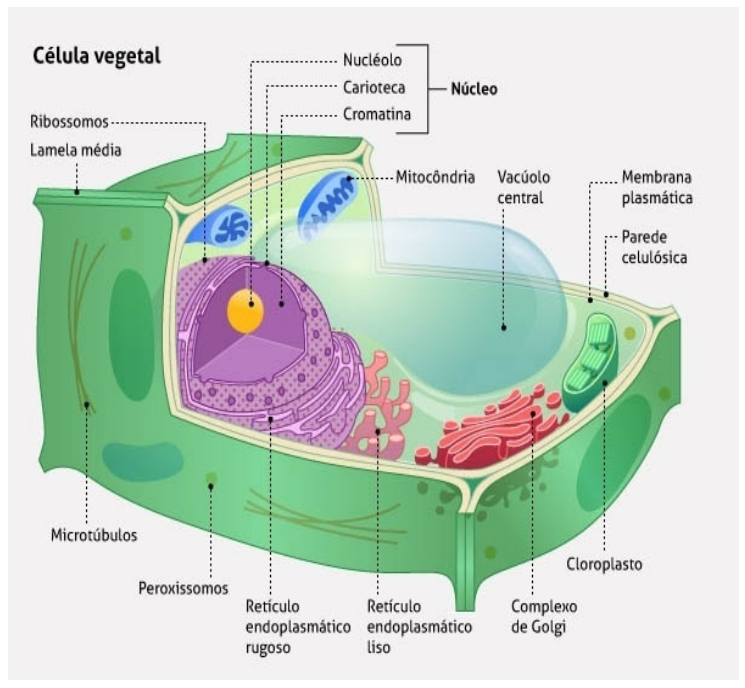

Figura 1. Ilustração célula vegetal

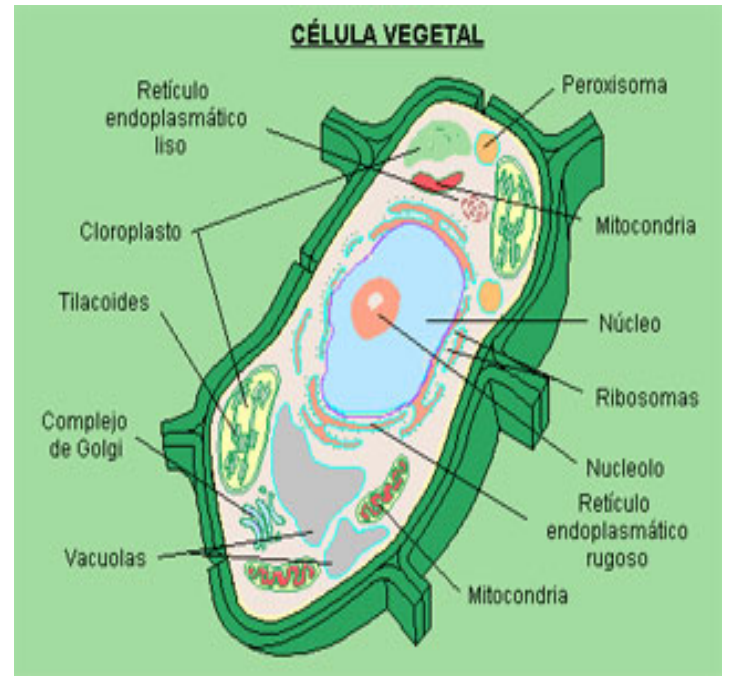

Figura 2: Ilustração célula animal. 

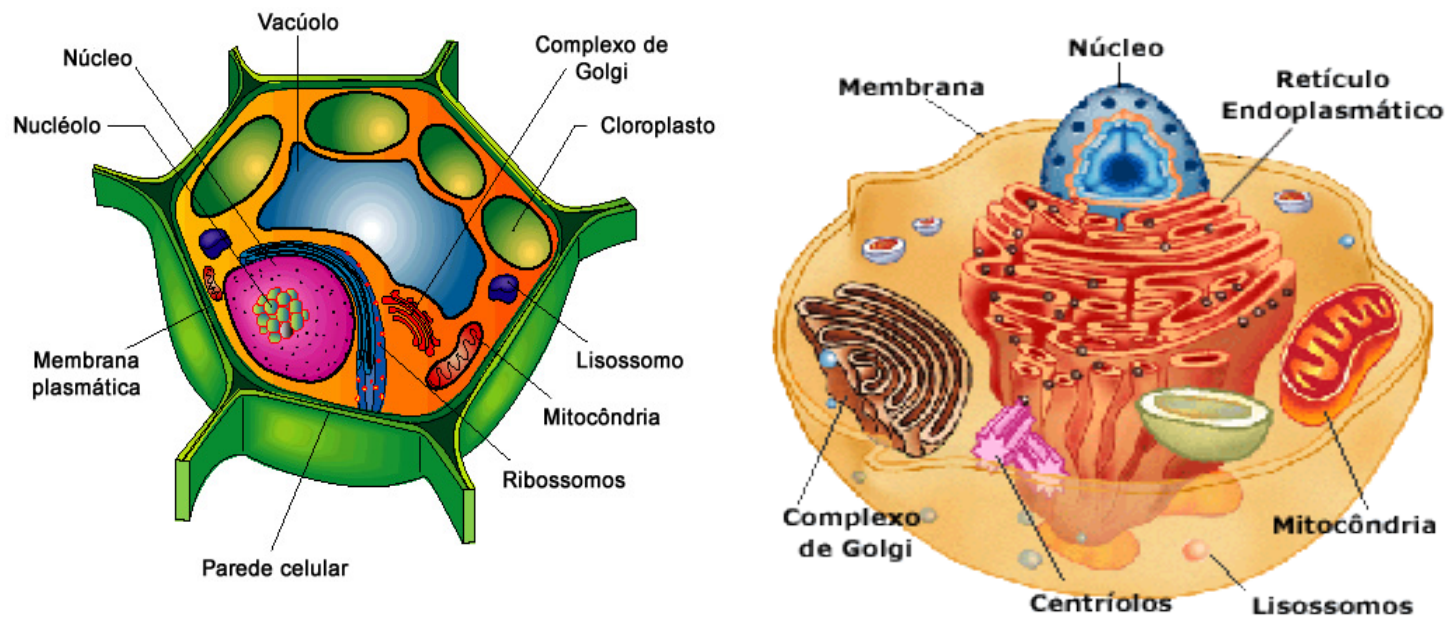

Figura 3. Ilustração célula vegetal.

Figura 4. Ilustração célula vegetal

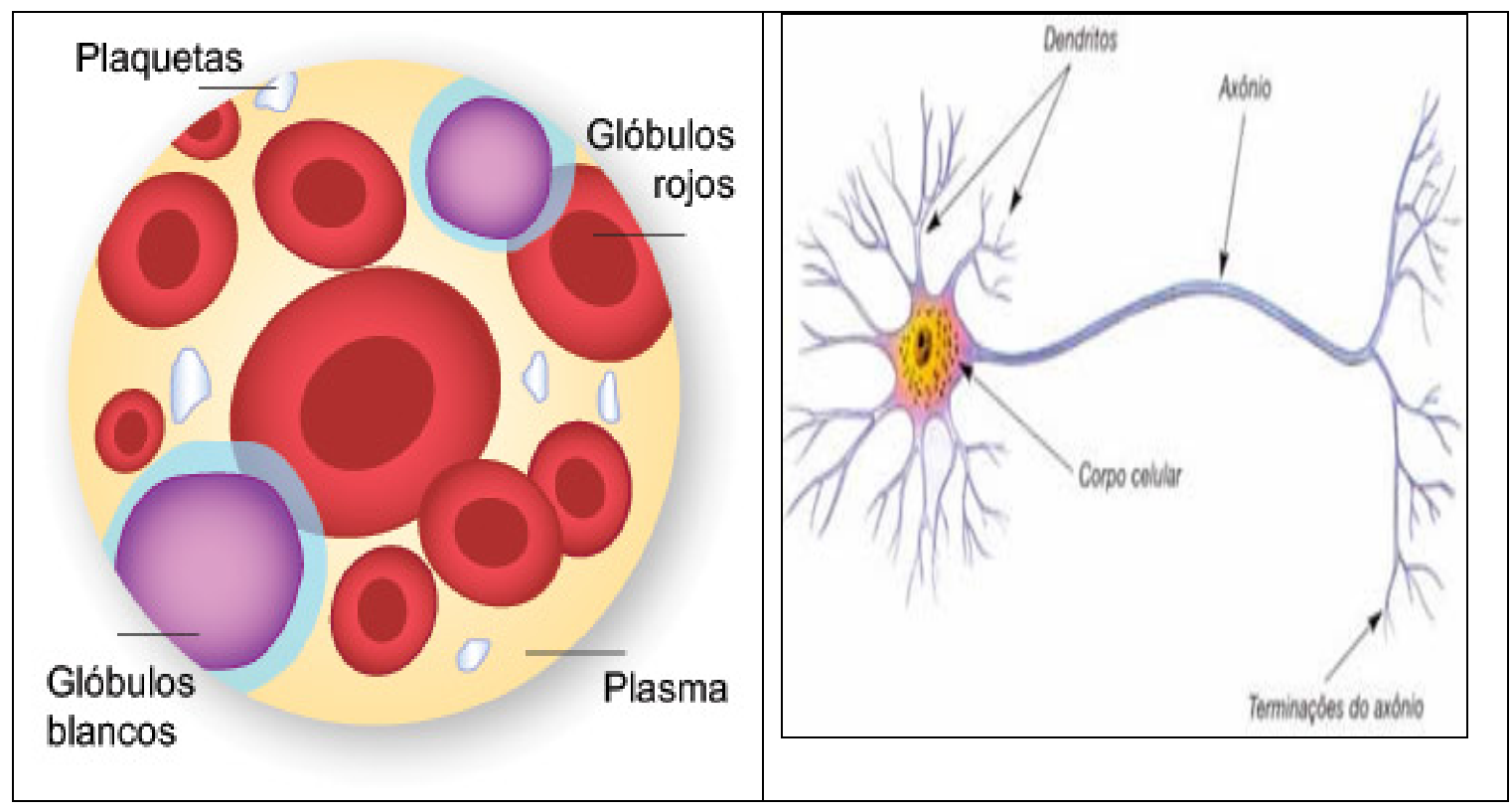

Figura 5. Ilustração célula animal.

Figura 6. Ilustração célula animal.

No segundo encontro foram distribuídas aos grupos fichas descritivas de modelos celulares, três vegetais e três animais, após a divisão dos conteúdos, foi explanado aos alunos resumos do funcionamento de cada célula e suas organelas. Conseguinte, foram distribuídasaos grupos listas de matérias que deveriam ser trazidos para a confecção das mesmas, onde constavam materiais recicláveis, como: tampas e garrafas PET, caixas pequenas e médias de papelão; canudos; pequenas bacias plásticas; plásticos diversos; embalagens de arroz, feijão, amendoim, chicletes e balinhas diversas. Outros materiaiscomo tesouras, colas, isopor, estiletes, lixas, pinceis e tintas, os bolsistas do PIBID trariam.

No terceiro encontrorealizado na sala de informáticaocorreu aconfecção dos modelos de células. Os materiais foram dispostos eorganizados no centro da sala e os grupos ao redor dos mesmos.Cada grupo orientado porbolsistasconfeccionaram os modelos em 01:40 h. Após o termino da práticaos modelos foram expostos à turma, supervisora do PIBID na escola e coordenação da mesma. Posteriormente foram levados ao laboratório de Ensino em Biologia localizado na Universidade Federal do Maranhão. 


\section{RESULTADOS E DISCUSSÃO}

Ao final da prática, seis modelos de células foram confeccionados. Quatro de células animais (Figuras 8, 10, 11 e 12) e duas de células vegetais (Figuras 7 e 9). Os modelos ficaram bastante fiéis, em estrutura, quando comparados aos dos modelos ilustrativos, tomado como base pelos grupos. É possível diferenciar as organelas citoplasmáticas em cada uma das células, ressaltando os materiais diversos para a montagem de cada uma delas e empenho dos grupos nas confecções. Foi observado que os alunos demonstraram maior interação com o conteúdo proposto eintegração com o grupo ao iniciaram o processo de confecção dos modelos de células. Quando souberam que eles mesmos iriam confeccioná-los, utilizando os materiais que eles encontraram para tal ato, demonstraram maior interesse pela prática. A motivação é um caminho para a melhoria da qualidade do ensino e da aprendizagem, conforme Knuppe (2006). Logo percebe-se que a forma que os alunos são incentivadosmuda consideravelmente os resultados na prática.

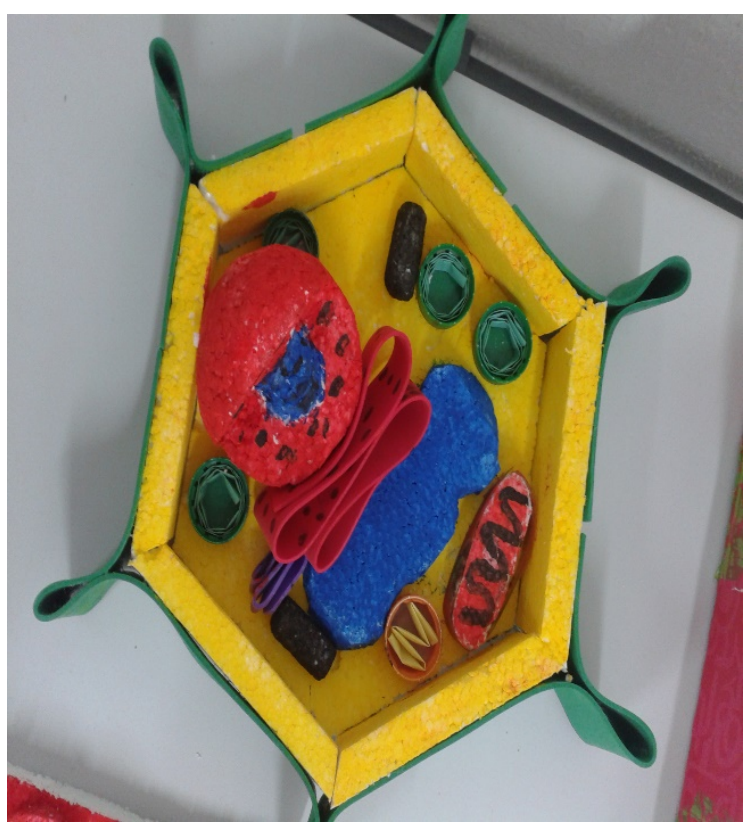

Figura 7. Célula vegetal confeccionada por alunos $7^{\circ}$ ano.

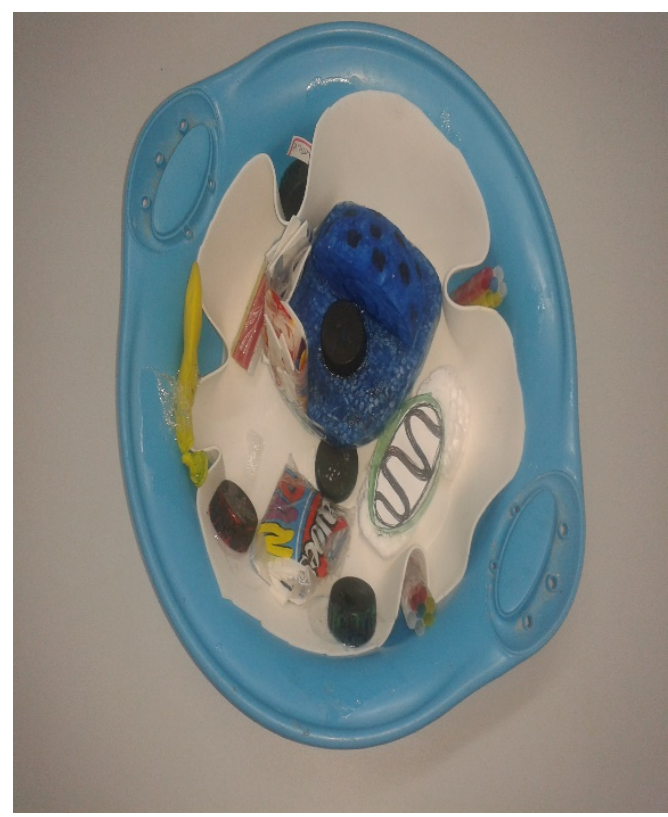

Figura 8. Célula animal confeccionada por alunos $7^{\circ}$ ano. 


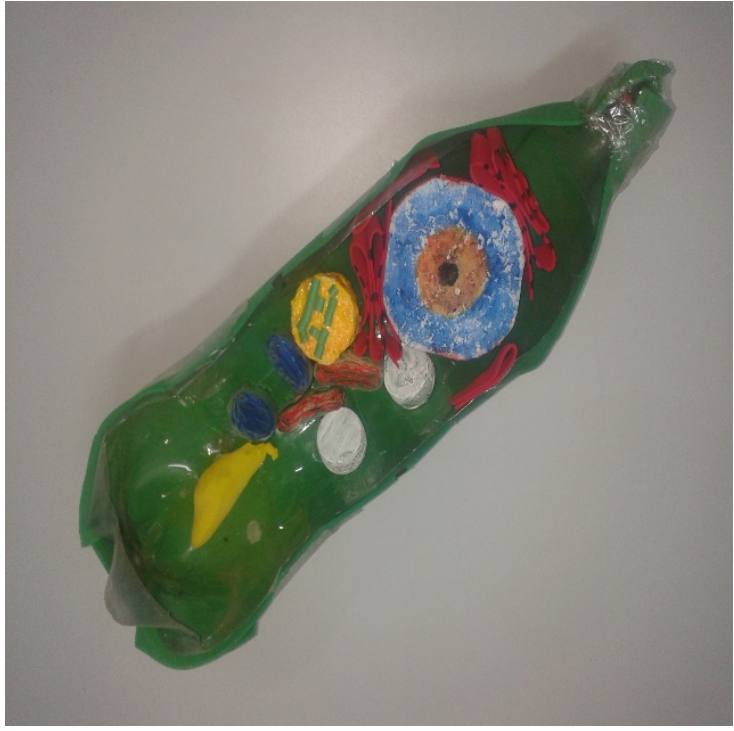

Figura 9. Célula vegetal confeccionada por alunos $7^{\circ}$ ano.

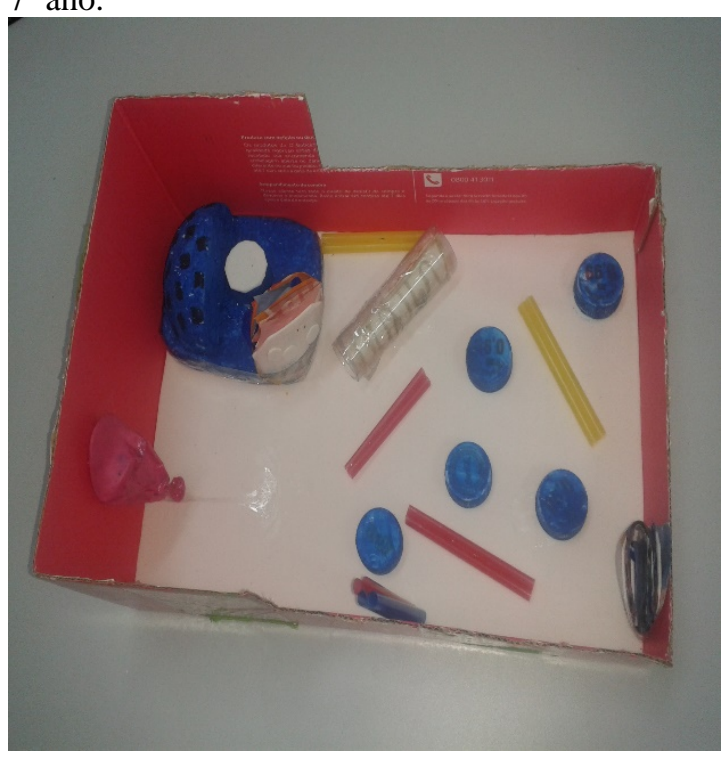

Figura 11. Célula animal confeccionada por alunos $7^{\circ}$ ano.

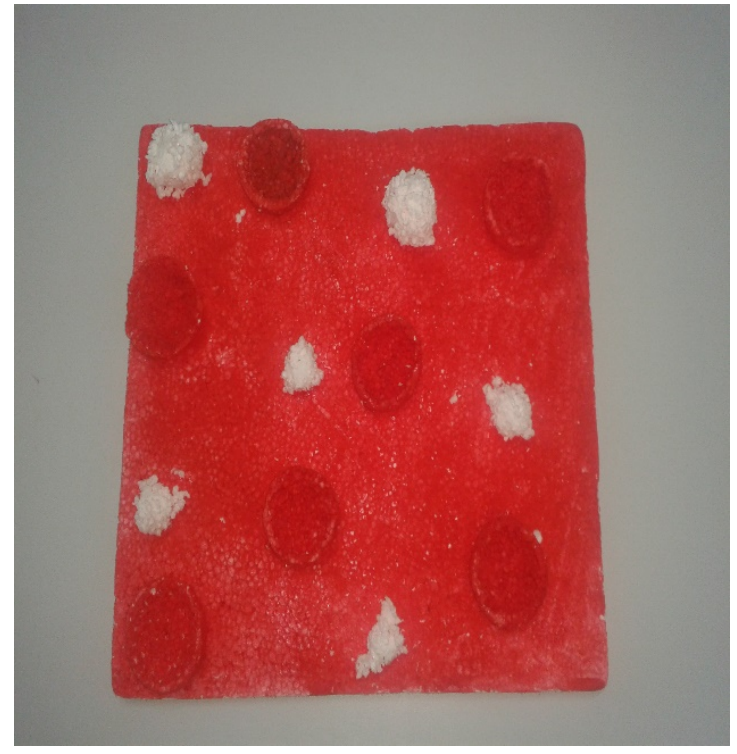

Figura 10. Célula animal confeccionada por alunos $7^{\circ}$ ano.

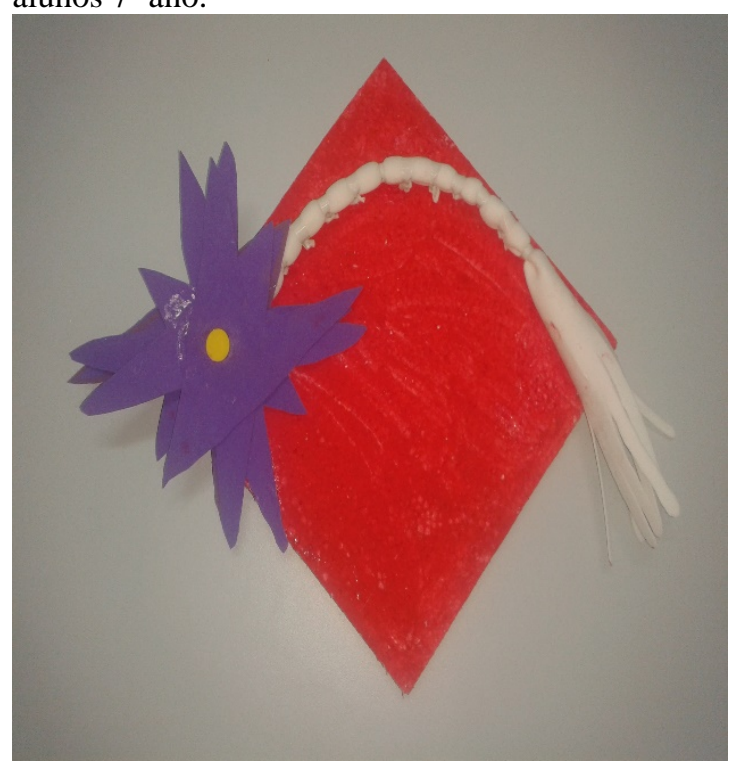

Figura 12. Célula animal confeccionada por alunos $7^{\circ}$ ano.

O método proposto de estimular o trabalho em equipe, além do uso de imaginação e criatividade dos alunos frente a uma problemática, modificou a atuação dos educandos na realização da atividade. Leva-se em conta que asala onde eles estudamgeralmente apresenta elevada temperatura, o quepode desfavorecer a atenção e concentração dos mesmos,visto que, na primeira visita, os alunos apresentaram comportamento de desordem e pouca atenção.Entretanto, na segunda e terceira visita utilizou-se uma sala diferente e climatizada. Assim, entende-se que a climatização do ambiente contribuiu para o aumento da concentração e um melhor desempenho dos alunos.

Segundo Huizinga (1996): "O lúdico lança sobre os alunos: fascínio eencanto. Isto foi percebido nos alunos, que durante a confecção dos modelos das células, estes se empenhavam e 
imaginavam formas de construir os modelos, havendo interações entre os grupos e maneiras de formular e reformular as ações durante todo o processo.

Os alunos demonstraram empenho e criatividade na realização da prática. As interações entre os gruposcontribuíram efetivamente no processo de ensino aprendizagem do conteúdo proposto.

\section{CONCLUSÕES}

Notou-se que a atividade funcionou como facilitador no ensino de ciências, tendo em vista a empolgação dos alunos durante todo o processo, ainda mais quando souberam que utilizariam materiais que iriam para o lixo. Os exemplares confeccionados apresentaram grande similaridade com modelos propostos, tanto para células animais quanto vegetais, demonstrando o desenvolvimento da imaginação e criatividadedos alunos envolvidos.

\section{REFERÊNCIAS}

BORGES, G. L. A. Formação de professores de Biologia, material didático e conhecimento escolar. Campinas, 2000. Tese (Doutorado em Educação) Faculdade de Educação, Universidade Estadual de Campinas;

HUIZINGA, J. Homo Ludens. São Paulo: Perspectiva, 1996.

KNUPPE, L. Motivação e desmotivação: desafio para as professoras do Ensino Fundamental. Educar em Revista, Curitiba, n. 27, 2006. Disponível em: http://dx.doi.org/10.1590/S010440602006000100017.

SARAIVA, J. A. F. O papel da experiência no ensino de ciências. In: GOULART, B. I. et al. (Org.). Educação uma perspectiva construtivista: reflexões de uma equipe multidisciplinar. São Paulo: Vozes. 1998.

SCHOENBERGER, M. R. M. A importância do lúdico na alfabetização. Disponível em: $<$ http://www.cefaprojuina.com/portal/index.php?option=com_content\&view=article\&id=428:i mportancia-ludico-alfabetizacao\&catid=57:autoria\&Itemid=71>. Acesso em: 9 maio 2014. 